\title{
Standardised assessment of functioning in ADHD: consensus on the ICF Core Sets for ADHD
}

\author{
Sven Bölte ${ }^{1,2,3}$ (D) Soheil Mahdi 1,2 $\cdot$ David Coghill 4,5,6 Susan Shur-Fen Gau ${ }^{7}$ Mats Granlund ${ }^{8} \cdot$ Martin Holtmann $^{9}$. \\ Sunil Karande ${ }^{10} \cdot$ Florence Levy $^{11} \cdot$ Luis A. Rohde ${ }^{12,13} \cdot$ Wolfgang Segerer $^{14} \cdot$ Petrus J. de Vries ${ }^{15} \cdot$ Melissa Selb $^{16}$
}

Received: 9 September 2017 / Accepted: 3 February 2018 / Published online: 12 February 2018

(c) The Author(s) 2018. This article is an open access publication

\begin{abstract}
Attention-deficit/hyperactivity disorder (ADHD) is associated with significant impairments in social, educational, and occupational functioning, as well as specific strengths. Currently, there is no internationally accepted standard to assess the functioning of individuals with ADHD. WHO's International Classification of Functioning, Disability and Health—child and youth version (ICF) can serve as a conceptual basis for such a standard. The objective of this study is to develop a comprehensive, a common brief, and three age-appropriate brief ICF Core Sets for ADHD. Using a standardised methodology, four international preparatory studies generated 132 second-level ICF candidate categories that served as the basis for developing ADHD Core Sets. Using these categories and following an iterative consensus process, 20 ADHD experts from nine professional disciplines and representing all six WHO regions selected the most relevant categories to constitute the ADHD Core Sets. The consensus process resulted in 72 second-level ICF categories forming the comprehensive ICF Core Set-these represented 8 body functions, 35 activities and participation, and 29 environmental categories. A Common Brief Core Set that included 38 categories was also defined. Age-specific brief Core Sets included a 47 category preschool version for 0-5 years old, a 55 category school-age version for 6-16 years old, and a 52 category version for older adolescents and adults 17 years old and above. The ICF Core Sets for ADHD mark a milestone toward an internationally standardised functional assessment of ADHD across the lifespan, and across educational, administrative, clinical, and research settings.
\end{abstract}

Keywords ADHD $\cdot$ Functioning $\cdot$ Assessment $\cdot$ Psychiatry $\cdot$ ICD $\cdot$ DSM $\cdot$ Consensus conference $\cdot$ ICF Core Sets

Sven Bölte

sven.bolte@ki.se

1 Center of Neurodevelopmental Disorders (KIND), Division of Neuropsychiatry, Department of Women's and Children's Health, Karolinska Institutet, Stockholm, Sweden

2 Center for Psychiatry Research, Stockholm County Council, Stockholm, Sweden

3 Child and Adolescent Psychiatry, Stockholm County Council, Stockholm, Sweden

4 Department of Paediatrics, University of Melbourne, Melbourne, Australia

5 Department of Psychiatry, University of Melbourne, Melbourne, Australia

6 Murdoch Children's Research Institute, Melbourne, Australia

7 Department of Psychiatry, National Taiwan University Hospital and College of Medicine, Taipei, Taiwan

8 CHILD, SIDR, School of Health and Welfare, Jönköping University, Jönköping, Sweden
9 LWL-University Hospital for Child and Adolescent Psychiatry, Psychotherapy and Psychosomatics, Ruhr University Bochum, Hamm, Germany

10 Learning Disability Clinic, Department of Pediatrics, Seth G.S. Medical College and K.E.M. Hospital, Mumbai, India

11 School of Psychiatry, Prince of Wales Hospital and University of New South Wales, Sydney, Australia

12 Division of Child and Adolescent Psychiatry, Hospital de Clinicas de Porto Alegre, Federal University of Rio Grande do Sul, Porto Alegre, Brazil

13 National Institute of Developmental Psychiatry for Children and Adolescents, Porto Alegre, Brazil

14 Swiss Paraplegic Research, Nottwil, Switzerland

15 Division of Child and Adolescent Psychiatry, University of Cape Town, Cape Town, South Africa

16 ICF Research Branch a cooperation partner within the WHO Collaborating Center for the Family of International Classifications in Germany (at DIMDI), Nottwil, Switzerland 


\section{Background}

With a worldwide estimated prevalence of between 3 and $7 \%$ [1-4], attention-deficit/hyperactivity disorder (ADHD) is a common neurodevelopmental condition defined by persistent age-inappropriate patterns of inattention, hyperactivity, and impulsivity [5]. ADHD is associated with challenges to functioning in daily life, including academic and vocational difficulties [6,7], social exclusion [8], and delinquency $[9,10]$. Co-exiting psychiatric issues are also common [11, 12]. Moreover, the overall quality of life is lower $[13,14]$ for those with ADHD and the risk for premature mortality is higher than in the non-ADHD population [15]. However, there is substantial variability in individual abilities, disability, and functional outcomes. For example, limited research suggests specific strengths related to ADHD, including sense of entrepreneurship [16] and innovative thinking [17]. The interindividual differences in functioning can be influenced by personal factors (e.g., self-esteem and self-efficacy) [18], participation in skill training programs [19], pharmacological treatments [20], and degree of family support [21], among others. While ADHD is predominantly operationalised in terms of its symptoms, research clearly suggests that ADHD should be viewed from a wider perspective, taking into account personal, social, and environmental factors, and functioning.

Such a bio-psycho-social perspective is promoted by the World Health Organization's (WHO) International Classification of Functioning, Disability and Health (ICF), offering a comprehensive, integrative framework of functioning, and disability [22]. The ICF complements the Diagnostic and Statistical Manual of Mental Disorders Fifth Edition (DSM-5) [5] and the International Classification of Diseases-Tenth Revision (ICD-10) [23], both of which focus on biomedical elements of ADHD. The holistic underpinning of the ICF is reflected in its classification structure [22]. The ICF comprises of two parts-(1) functioning and disability and (2) contextual factors. Functioning and disability include body functions (i.e., physiological and mental functions of the body system), body structures (i.e., anatomical parts of the body), activities (i.e., execution of tasks), and participation (i.e., involvement in life situations). Contextual factors consist of environmental factors (i.e., factors not inherent to the individual, e.g., family, work, recreational opportunity, government agencies, laws, and societal attitudes) as well as personal factors (i.e., personal experience, race, gender, age, educational level, and coping styles). Even though personal factors are part of the ICF framework, these are currently not classified given their extensive cultural and social diversity [22]. All other components of the ICF are divided into "chapters" that have hierarchically organised "categories" with up to three levels of increasing detail. This hierarchy is illustrated in Fig. 1 with an example from the activities and participation component.

In 2007, a Child and Youth version of the ICF, the ICFCY, was published [24]. The ICF-CY encompasses all the categories of the reference version of the ICF plus additional ones that capture the functional characteristics and environments of developing individuals. Altogether, it comprises 1685 categories: 531 in the body functions component; 329 in body structures; 552 in activities and participation; and 273 environmental factors. For the development of the ICF Core Sets for ADHD described here, we decided to use the more comprehensive ICF-CY (but referred to as "ICF" from now on).

The use of the ICF in managing ADHD supports emphasis on individual abilities, disabilities, and the impact of the specific context on individual functioning. This take on the impact of ADHD is meaningful for many reasons [25, 26]. First, functioning is often perceived as less stigmatising than diagnosis or psychopathology; the ICF offers a framework that can be used to assess strengths in addition to impairments. Furthermore, functional problems are often the reason for the initial referral to services and an important focus for interventions. Given this, these functional aspects are likely to be more tangible and meaningful to individuals with ADHD, their families and society as a whole than diagnosis and psychopathology. Describing an individual's functioning can also be useful in identifying real-life challenges, guiding treatment planning [27], and enhancing communication between individuals with ADHD and their environment and with professionals. Moreover, clarifying

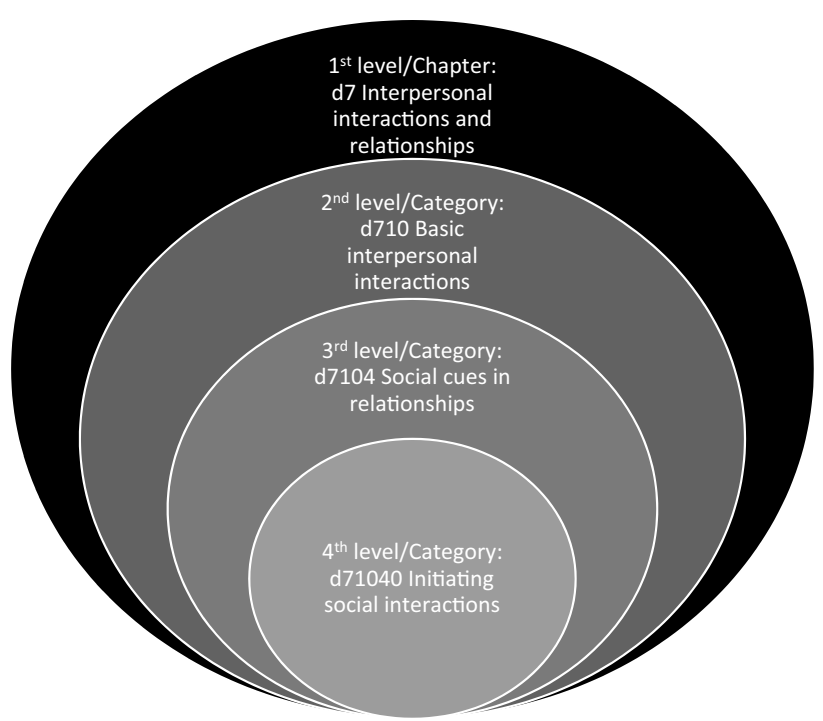

Fig. 1 Example of the hierarchically organised category structure of the ICF 
the functioning of individuals or a group of individuals has potential for improving the calculation of health-related service costs $[28,29]$. Finally, the ICF highlights the possible influence of the environment - positive and/or negativeon an individual's outcome. Understanding this modifying role of environmental factors provides the basis for possible adaptation of specific factors to improve outcome.

In spite of all these positive aspects, applying the ICF in day-to-day settings can be challenging. For one, compared to ICD and DSM, the ICF is much less well known and has not yet been widely accepted by professionals and researchers in the ADHD community. Moreover, its exhaustive comprehensiveness can make its use in daily practice difficult and timeconsuming. In practice, only a fraction of the ICF categories are needed when evaluating functioning of individuals with specific health conditions. To address these issues, shortlists of ICF categories relevant for specific health conditions, socalled 'ICF Core Sets', have been developed [30].

The development of ICF Core Sets involves a rigorous scientific procedure aimed at reducing the number of ICF categories to those that are most significant for a given condition. This procedure comprises of four international, multiperspective preparatory studies-a comprehensive scoping review, an expert survey, a qualitative study and a clinical study, and a multidisciplinary and expertise-based decisionmaking and consensus (conference) process [30].

ICF Core Sets have been developed for diagnoses such as cerebral palsy [31], depression [32], and bipolar disorder [33], but not yet for any DSM-5 defined neurodevelopmental disorder. For this reason, the Karolinska Institutet Center of Neurodevelopmental Disorders (KIND), in collaboration with the ICF Research Branch, a cooperation partner within the WHO Collaboration Centre for the Family of International Classifications in Germany (at DIMDI), and the European Network for Hyperkinetic Disorders (EUNETHYDIS), initiated the development of ICF Core Sets for ADHD [34]. The objective of this paper is to provide a summary of the international consensus conference, where the ICF Core Sets for ADHD were created.

\section{Method}

\section{Overall process}

The ICF Core Sets for ADHD were generated at a specially convened consensus conference, by a multidisciplinary and international group of experts. This group based their decision-making on evidence generated in the four preparatory studies, i.e., comprehensive scoping review, expert survey, qualitative study and clinical study, and on their own knowledge and experience with persons living with ADHD. Each preparatory study resulted in a set of candidate categories, i.e., a selection of ICF categories that represented the different perspectives captured in each of the studies. Throughout the decision-making and consensus conference, the participants were reminded to consider the preparatory studies results in their discussions and voting.

\section{Preparatory studies}

The study designs and methodologies were different in each of the preparatory studies, but candidate categories for ICF Core Sets for ADHD were identified similarly. After extracting functioning concepts from the respective data sets collected in each preparatory study, concepts were linked to the ICF using established linking rules [35] and a frequency analysis was conducted. The most frequently reported categories in each study were included in the list of candidate categories for that study. The preparatory studies included:

1. A scoping review of functioning data gathered by 80 ADHD-related outcome studies that were identified through a comprehensive search using scientific databases (e.g., Medline, PubMed, and Cinahl) [36].

2. An international survey of ADHD experts which collected the views and opinions of 174 experts across 11 professional disciplines from 45 countries and all WHO world regions [37].

3. A qualitative study that involved focus group discussions and semi-structured interviews of individuals with ADHD, family members, and professional caregivers from 16 stakeholder groups in 5 countries from $5 \mathrm{WHO}$ world regions [38].

4. A clinical cross-sectional study [39] which, unlike the other preparatory studies, derived candidate categories from the extended ICF checklist that clinicians and clinical researchers used to assess 112 individuals with ADHD recruited at 9 clinical sites in 8 countries in 4 different WHO world regions. Since each ICF checklist item already indicated a corresponding ICF category, ICF linking was not conducted here.

A detailed description of each study can be found in separate scientific publications [36-39].

\section{Consensus conference}

\section{Participants}

To generate the first ICF Core Sets for ADHD, international experts were invited to participate in a three-day iterative decision-making and consensus conference that took place at the KIND center in Stockholm (Sweden) in September 2016. Experts had to meet the following inclusion criteria to be eligible for conference participation: (1) a professional 
background in childhood disability, which included psychiatry, psychology, psychotherapy, social work, special education, speech-language pathology, nursing, occupational therapy, paediatrics, and physiotherapy, (2) at least 5 years of working experience with children, adolescents, or adults with ADHD, and (3) fluency in English. The nomination of experts was predominantly made by the Project Steering Committee, a group of key opinion leaders in the field of ADHD or experts in ICF. The Steering Committee included clinicians, educators, researchers, and self-advocates from all six WHO regions (see acknowledgement and authors DC, SFG, MG, MH, SK, FL, LR, PdV). To achieve a broad representation of professional backgrounds and WHO world regions, the Steering Committee members were asked to nominate experts who matched their own professional field and $\mathrm{WHO}$ world region. Altogether, invitations to participate in the consensus conference were sent to 30 international ADHD experts.

\section{Procedure}

The consensus conference followed a standardised iterative decision-making and consensus (voting) process established for ICF Core Set development. In accordance with the previous ICF Core Set projects, comprehensive and Brief (Common) ICF Core Sets were developed [31, 32]. In addition, based on a decision made by the Steering Committee, three age-specific Brief Sets were also developed: a preschool set (ages 0-5 years), a school-age set (ages 6-16), and an older adolescent and adult set for individuals 17 years and older (Fig. 2) [30]. Throughout the voting process, a specialized data analysis program in MS Office Access was employed. This data program displayed the category descriptions and corresponding frequencies of the candidate categories from each preparatory study, tracked the expert votes, and generated summary results that informed the subsequent steps of the voting procedure. A condensed ICF workshop was also held prior to starting the formalized voting process to familiarize the participating ADHD experts with the ICF and prepare them for the iterative decision-making and consensus (voting) process. The voting process comprised two stages-stage 1 to generate the Comprehensive ICF Core Set for ADHD and stage 2 to generate the brief versions. Stage 1 was completed by alternating discussions and voting in working group (Votes A and B) and plenary sessions (Votes $\mathrm{C}$ to E). Stage 2 involved a two-round ranking and cut-off exercise for each brief set.

\section{Stage 1}

For the working group (WG) discussions and voting of Votes A and B, the ADHD experts were divided into three groups of 6 or 7 participants. Participants remained in the same WG throughout stage 1. In determining the composition of the WGs, efforts were made to ensure a balanced representation of professional disciplines, WHO world regions, and gender. A WG leader was appointed for each group to moderate the WG discussions and voting procedure. To support the WG leader, two assistants were assigned to each WG to present the results from the preparatory studies for each candidate category, make notes of the discussion, and enter the votes into the data analysis program. The WG leader called for arguments for and against including the individual candidate categories, and encouraged the experts to consider the preparatory study results, their own expertise in ADHD, as well as relevant issues relating to country and cultural applicability. Since the WG leaders were allowed to vote, they were instructed to communicate objectively and ensure that each WG participant had the opportunity to express an opinion before voting. To avoid leader bias, the WG leaders were also instructed to give their own feedback only until after several other group members had already provided their comments. Voting was conducted through a show of hands.

As in the previous ICF Core Set projects [31,33], for a specific category to be automatically included in the Comprehensive Core Set for ADHD in Votes A and B, at least $75 \%$ of the experts had to vote in favour of including that category. Categories that received $40 \%$ positive votes or less were automatically excluded from the comprehensive set. Individual candidate categories were considered "ambiguous" if more than $40 \%$ but less than $75 \%$ of the experts voted to include that category. Ambiguous categories were carried over to the next session for rediscussion and a new voting round occurred. Between the WG sessions in Votes A and B, a plenary session took place to review Vote A results and to enable the participants to again present pros and cons for including each of the ambiguous categories. Ambiguous categories that remained after Vote B were re-discussed in the subsequent plenary session, during which Vote $\mathrm{C}$ took place. In Vote $\mathrm{C}$, the majority ( $>50 \%$ ) of the participants had to agree to include the ambiguous category for it to be part of the Comprehensive Core Set.

Up to this point, the categories that were already included in the Comprehensive Core Set for ADHD were at secondlevel. In Vote D, the experts were asked to decide whether these second-level categories were specific enough to describe the functioning of individuals with ADHD or "dive deeper", i.e., continue to Vote E, during which they had the opportunity to consider replacing the second-level category with more specific third- or fourth-level categories. As only $40 \%$ of the experts voted for diving deeper, the categories all remained at the second level. At this point, Stage 1 was considered complete and the Comprehensive ICF Core Set for ADHD was finalized. 


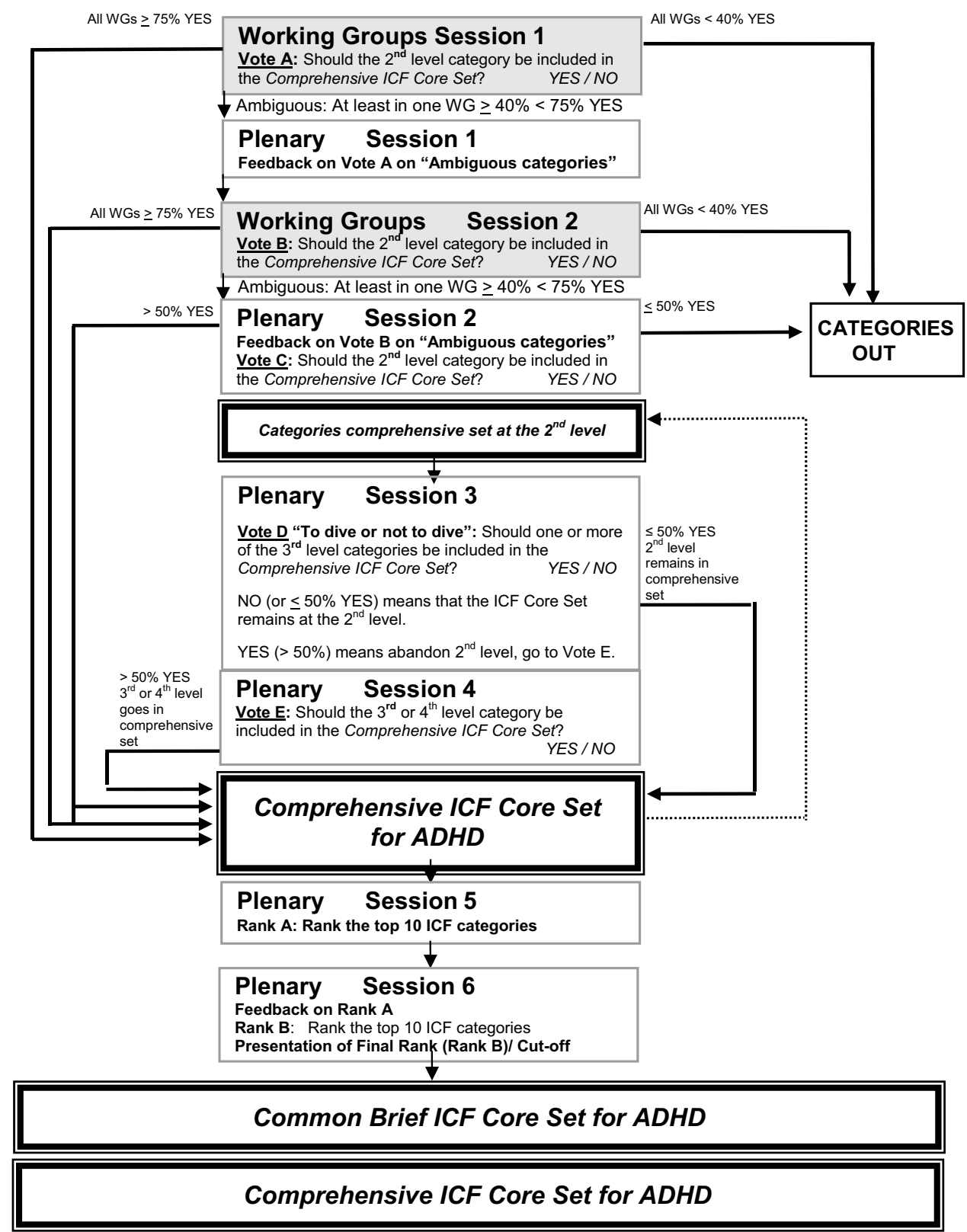

\begin{tabular}{|l|}
\hline Plenary $\quad$ Session 7 \\
Rank A: Rank the top 10 ICF categories \\
\begin{tabular}{|l} 
Plenary Session 8 \\
Rank B: Rank the top 10 ICF categories \\
Presentation of Final Rank (Rank B) \\
Cut-off
\end{tabular} \\
\hline $\begin{array}{c}\text { Brief ICF Core Set for ADHD } \\
\text { 0-5 years of age }\end{array}$ \\
\hline
\end{tabular}

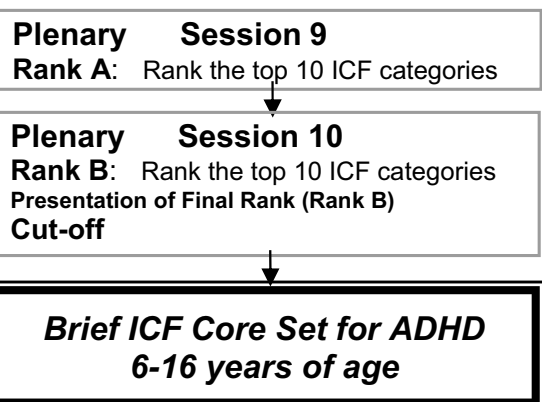

Plenary Session 11

Rank A: Rank the top 10 ICF categories

Plenary Session 12

Rank B: Rank the top 10 ICF categories Presentation of Final Rank (Rank B)

Cut-off

Brief ICF Core Set for ADHD $\geqq 17$ years of age

Fig. 2 Iterative decision-making process at the consensus meeting 


\section{Stage 2}

In stage 2, the brief common set and the three age-specific Brief Sets were developed by conducting a two-round ranking and cut-off exercise for each set. In deciding on the ranking and cut-off, the experts were reminded that the Brief Sets should comprise the fewest number of categories possible while still capturing the most essential.

In the first ranking round to develop the Common Brief Set, each expert received a handout with all the categories from the Comprehensive Core Set for ADHD organised according to ICF component, and were instructed to rank the top 10 most essential categories for each ICF component from 1 to 10 , with "1" being most essential. The ranking results of each expert were analysed using descriptive statistics and combined to generate a common ranking. The common ranking was then presented and the participating experts were given the opportunity to discuss reasons for their ranking decision and arguments for including selected categories. Subsequently, the second ranking round began following the same procedure. After conclusion of the second ranking round, the experts were asked to choose a cutoff, i.e., the number of categories per ICF component that would be crucial to include in the brief common set. The same ranking and cut-off procedure was repeated for each of the age-specific brief sets. However, the starting list of categories did not include the categories of the Common Brief Set, since these were automatically included in each of the agespecific brief sets. Categories that were included in all the three age-specific brief sets were integrated retrospectively in the Common Brief Set.

\section{Results}

The scoping review identified 50 [36], the international expert survey 53 [37], the qualitative study 82 [38], and the clinical cross-sectional study 109 second-level candidate categories [39]. Taken together, the four preparatory studies identified 132 unique second-level ICF candidate categories. The majority of the categories came from the activities and participation component $(k=55,42 \%)$, followed by body functions $(k=37,28 \%)$, environmental factors $(k=36$, $27 \%)$, and body structures $(k=4,3 \%)$. Table 1 summarizes the second-level candidate ICF categories that were identified across the four preparatory studies.

\section{Consensus conference experts}

Of the 30 experts who were invited to participate in the international consensus conference, 8 declined due to other commitments and 2 did not respond to the invitation. In total, 20 experts ( 14 females and 6 males) from 12 countries
(Australia, Czech Republic, Germany, India, Mexico, Portugal, Puerto Rico, Saudi Arabia, South Africa, Sweden, United Kingdom, and United States), representing all six WHO world regions, participated in the consensus conference (see acknowledgement). Table 2 summarizes the participating experts by WG, gender, professional background, country, and WHO world region.

\section{Comprehensive ICF Core Set for individuals with ADHD}

Table 3 shows the categories included in the Comprehensive ICF Core Set for ADHD, along with the percentage of agreement for each category that was included. Of the 132 second-level candidate categories that were identified in the preparatory studies, $72(55 \%)$ were included in the Comprehensive Core Set. A large majority of the included categories were from the activities and participation component $(k=35,49 \%)$, followed by environmental factors ( $k=29,40 \%)$ and body functions $(k=8,11 \%)$. No body structures were included. All nine chapters from the activities and participation component and all five chapters of the environmental factors were represented in the Comprehensive Core Set. All body functions categories, except from b760 Control of voluntary movement functions, were mental functions. The most frequently covered chapters were e4 Attitudes $(k=10,14 \%)$ and e3 Support and relationships $(k=8,11 \%)$ from the environmental factor component.

\section{Common Brief ICF Core Set for individuals with ADHD}

Table 4 lists the 38 second-level ICF categories included in the Common Brief set for ADHD, along with their final rank order. It comprises the 31 categories that were included following the initial ranking and cut-off process and additional 7 categories that were found to be common to all of the agespecific brief sets. The Common Brief Set categories came from the environmental factors component $(k=17,45 \%)$, activities and participation ( $k=14,37 \%)$, and body functions $(k=7,18 \%)$. The most frequently covered chapters were b1 Mental functions ( $k=7,18 \%)$, e4 Attitudes $(k=6$, $16 \%)$, and e3 Support and relationships $(k=5,13 \%)$.

\section{Brief ICF Core Set for preschool-age children (0-5 years old)}

Table 5 summarizes the categories included in the Brief Set for the preschool-age group of 0-5 years old, along with their final rank order. This specific Brief Set consisted of 47 second-level ICF categories across three different components: environmental factors $(k=20,43 \%)$, activities and participation $(k=19,40 \%)$, and body functions 
Table 1 Candidate ICF categories from each respective preparatory study

\begin{tabular}{lll}
\hline Second-level ICF category & Scoping review Expert survey & $\begin{array}{l}\text { Qualitative } \\
\text { study }\end{array}$ \\
\hline
\end{tabular}

Body function

b110 Consciousness functions $\quad \mathrm{X}$

b114 Orientation functions $\quad X$

b117 Intellectual functions

b122 Global psychosocial functions

b125 Dispositions and intra-personal functions

b126 Temperament and personality functions

b130 Energy and drive functions

b134 Sleep functions

b140 Attention functions

b144 Memory functions

b147 Psychomotor functions

b152 Emotional functions

b156 Perceptual functions

b160 Thought functions

b163 Basic cognitive functions

b164 Higher level cognitive functions

b167 Mental functions of language

b172 Calculation functions

b180 Experience of self and time functions

b220 Sensations associated with the eye and adjoining structures

b235 Vestibular functions

b240 Sensations associated with hearing and vestibular function

b265 Touch function

b280 Sensation of pain

b330 Fluency and rhythm of speech functions

b410 Heart functions

b455 Exercise tolerance functions

b510 Ingestion functions

b525 Defecation functions

b530 Weight maintenance functions

b535 Sensations associated with the digestive system

b640 Sexual functions

b710 Mobility of joint functions

b735 Muscle tone functions

b760 Control of voluntary movement functions

b765 Involuntary movement functions

b840 Sensation related to the skin

Body structures

s110 Structure of brain

s710 Structure of head and neck region

s730 Structure of upper extremity

s750 Structure of lower extremity

Activities and participation

d110 Watching

d115 Listening

d140 Learning to read

d145 Learning to write
$X$
$X$

$\mathrm{X}$

$\mathrm{X}$

$\mathrm{X}$

$\mathrm{X}$

$\mathrm{X}$

$\mathrm{X}$

$\mathrm{x}$

$\mathrm{X}$

$\mathrm{X}$

$\mathrm{X}$

$\mathrm{X}$

$\mathrm{X}$

$\mathrm{X}$

$\mathrm{X}$

$\mathrm{x}$

$\mathrm{X}$

study

$\begin{array}{llll} & \mathrm{X} & \mathrm{X} & \\ \mathrm{X} & \mathrm{X} & \mathrm{X} \\ \mathrm{X} & \mathrm{X} & \mathrm{X} & \mathrm{X} \\ \mathrm{X} & \mathrm{X} & \mathrm{X} & \mathrm{X} \\ \mathrm{X} & \mathrm{X} & \mathrm{X} & \mathrm{X} \\ \mathrm{X} & \mathrm{X} & \mathrm{X} & \mathrm{X} \\ \mathrm{X} & \mathrm{X} & \mathrm{X} & \mathrm{X} \\ \mathrm{X} & \mathrm{X} & \mathrm{X} & \mathrm{X} \\ \mathrm{X} & \mathrm{X} & \mathrm{X} & \mathrm{X} \\ \mathrm{X} & \mathrm{X} & \mathrm{X} & \mathrm{X} \\ \mathrm{X} & \mathrm{X} & \mathrm{X} & \mathrm{X} \\ \mathrm{X} & & \mathrm{X} & \mathrm{X} \\ \mathrm{X} & & & \mathrm{X} \\ \mathrm{X} & \mathrm{X} & \mathrm{X} & \mathrm{X} \\ \mathrm{X} & & \mathrm{X} & \mathrm{X}\end{array}$

X

X

X

X

X

X

$\mathrm{X}$

X

$\mathrm{X}$

$\mathrm{X}$

X

$\mathrm{X}$

$\mathrm{X}$

$\mathrm{X}$

$\mathrm{X}$

$\mathrm{x}$

$\mathrm{X}$

$\mathrm{X}$

$\begin{array}{cc}X & X \\ X & X \\ & X \\ & X \\ & X \\ X & X \\ X & X\end{array}$

X

$\mathrm{X}$

$\mathrm{X}$

$\mathrm{x}$

$\mathrm{X}$

$\mathrm{X}$

$\mathrm{X}$

$\mathrm{X}$

$\mathrm{X}$

$\mathrm{X}$

$\mathrm{X}$

$\mathrm{X}$

$\mathrm{X}$

X

X 
Table 1 (continued)

Second-level ICF category Scoping review Expert survey

Qualitative

Clinical study study

d150 Learning to calculate

d160 Focusing attention

d161 Directing attention

d166 Reading

d170 Writing

d172 Calculating

d175 Solving problems

d177 Making decisions

d210 Undertaking a single task

d220 Undertaking multiple tasks

d230 Carrying out daily routine

d240 Handling stress and other psychological demands

d250 Managing one's own behaviour

d310 Communicating with—receiving—spoken messages

d315 Communicating with—receiving-nonverbal messages

d330 Speaking

d335 Producing nonverbal messages

d350 Conversation

d440 Fine hand use

d446 Fine foot use

d455 Moving around

d470 Using transportation

d475 Driving

d510 Washing oneself

d520 Caring for body parts

d530 Toileting

d540 Dressing

d550 Eating

d570 Looking after one's health

d571 Looking after one's safety

d620 Acquisition of goods and services

d630 Preparing meals

d640 Doing housework

d650 Caring for household objects

d660 Assisting others

d710 Basic interpersonal interactions

d720 Complex interpersonal interactions

d730 Relating with strangers

d740 Formal relationships

d750 Informal social relationships

d760 Family relationships

d770 Intimate relationships

d820 School education

d825 Vocational training

d830 higher education

d845 Acquiring, keeping, and terminating a job

d850 Remunerative employment

d870 Economic self-sufficiency

\section{$\mathrm{X}$}

$\mathrm{X}$

$\mathrm{X}$

$\mathrm{X}$

$\mathrm{X}$

$\mathrm{X}$

$\mathrm{X}$

$\mathrm{X}$

$\mathrm{X}$

X

X

X

X

X

$\mathrm{X}$

X

$\mathrm{X}$

$\mathrm{X}$

$\mathrm{X}$

X
X

X

X

$\mathrm{X}$

$\mathrm{X}$

$X \quad X$

X

$\mathrm{X}$

$\mathrm{X}$

X

X

X

X

$\mathrm{X}$

$\mathrm{X}$

$\begin{array}{ll}X & X \\ X & X\end{array}$

$X$

$\mathrm{X}$

X

$\mathrm{X}$

X

X

X

X

X

X

X

X

X

X

X

$\mathrm{X}$

$\mathrm{X}$

X

$\mathrm{X}$

X

X

$\mathrm{X}$

X

X

X

X

X

X

$\mathrm{X}$

X

X X

$\mathrm{X}$

X X

X X

X X

$\mathrm{X}$

X X

X X

X X

$\mathrm{X}$

$\begin{array}{lll}X & X & X \\ X & & X\end{array}$

$\mathrm{X}$

X $\quad$ X

$\mathrm{X}$ 
Table 1 (continued)

Second-level ICF category

Scoping review Expert survey Qualitative

Clinical study study

d880 Engagement in play

d910 Community life

d920 Recreation and leisure

Environmental factors

e110 Products or substances for personal consumption

e115 Products and technology for personal use in daily living

e120 Products and technology for personal indoor and outdoor mobility and transportation

e125 Products and technology for communication

e130 Products and technology for education

e140 Products and technology for culture, recreation and sport

e165 Assets

e225 Climate

e240 Light

e250 Sound

e310 Immediate family

e315 Extended family

e320 Friends

e325 Acquaintances, peers, colleagues, neighbours and community members

e330 People in positions of authority

e340 Personal care providers and personal assistants

e355 Health professionals

e360 Other professionals

e410 Individual attitudes of immediate family members

e415 Individual attitudes of extended family members

e420 Individual attitudes of friends

e425 Individual attitudes of acquaintances, peers, colleagues, neighbours, and X community members

e430 Individual attitudes of people in positions of authority

e440 Individual attitudes of personal care providers and personal assistants

e450 Individual attitudes of health professionals

e455 Individual attitudes of other professionals

e460 Societal attitudes

e465 Social norms, practices, and ideologies

e535 Communication services, systems, and policies

e550 Legal services, systems, and policies

e570 Social security services, systems, and policies

e575 General social support services, systems, and policies

e580 Health services, systems, and policies

e585 Education and training services, systems, and policies

e590 Labour and employment services, systems, and policies

e595 Political services, systems, and policies

X $\quad X$

$\mathrm{X}$

$\mathrm{X}$

X

X

$\mathrm{X}$

$\begin{array}{lll}X & X & X\end{array}$

$\mathrm{X}$

$\mathrm{X}$

$\mathrm{X} \quad \mathrm{X}$

$\mathrm{X} \quad \mathrm{X} \quad \mathrm{X}$

$\mathrm{X}$

$\begin{array}{ll}X & X \\ X & \end{array}$

$\mathrm{X} \quad \mathrm{X}$

$\mathrm{X}$

$\mathrm{X}$

$X$

$\mathrm{X}$
$\mathrm{X}$

$\mathrm{X}$

$\mathrm{X}$

$\mathrm{X}$

$\mathrm{X}$

$\mathrm{X}$

$\mathrm{X}$

$\mathrm{X}$

X $\quad X$

$\mathrm{X} \quad \mathrm{X}$

$\begin{array}{ll}X & X \\ X & x\end{array}$

$X \quad X$

$\mathrm{X}$

X

$\mathrm{X}$

$\mathrm{X}$

$\mathrm{X}$

$\mathrm{X}$

$\mathrm{X}$

$\mathrm{X}$

$\mathrm{X}$

$\mathrm{X}$

$\mathrm{X}$

X

X X

X X X

$\mathrm{X}$

$\mathrm{X}$

$\mathrm{X}$

$\mathrm{X}$

X

X

X

X X

X X

X X 
Table 2 Composition of the Working Groups

\begin{tabular}{|c|c|c|c|c|c|c|}
\hline WG 1 & WG 2 & WG 3 & Gender & Profession & Country & WHO region \\
\hline & & 1 & Male & Nurse & Portugal & EURO \\
\hline 1 & & & Female & OT & South Africa & AFRO \\
\hline \multirow[t]{4}{*}{1} & & & Female & OT & United Kingdom & EURO \\
\hline & 1 & & Female & OT & Sweden & EURO \\
\hline & & 1 & Female & OT & Sweden & EURO \\
\hline & 1 & & Female & PedMD & Sweden & EURO \\
\hline \multirow[t]{3}{*}{1} & & & Male & $\mathrm{PT}$ & Germany & EURO \\
\hline & 1 & & Male & PsychMed & South Africa & AFRO \\
\hline & & 1 & Male & PsychMed & Australia & WPRO \\
\hline 1 & & & Male & PsychMed & Mexico & AMRO \\
\hline \multirow[t]{7}{*}{1} & & & Female & Psychol. & Sweden & EURO \\
\hline & 1 & & Female & Psychol. & Sweden & EURO \\
\hline & & 1 & Female & Psychol. & Sweden & EURO \\
\hline & & 1 & Female & Psychol. & Saudi Arabia & EMRO \\
\hline & 1 & & Female & Psychol. & India & SEARO \\
\hline & 1 & & Male & SW & Puerto Rico & AMRO \\
\hline & & 1 & Female & SW & United States & AMRO \\
\hline 1 & & & Female & Special Ed. & India & SEARO \\
\hline & 1 & & Female & Special Ed. & Czech Republic & EURO \\
\hline 1 & & & Female & SLP & Sweden & EURO \\
\hline
\end{tabular}

$W G 1$ working group $1, W G 2$ working group 2, WG 3 working group 3, OT occupational therapist, $P T$ physiotherapist, PedMed paediatrician, PsychMed psychiatrist, Psychol. psychologist, SW social worker, Special Ed special educator, SLP speech-language pathologist, AFRO Africa, EMRO Eastern Mediterranean, EURO Europe, SEARO South East Asia, AMRO The Americas, WPRO Western Pacific $(k=8,17 \%)$. All five chapters of the environmental factors component were represented in the Brief Set, and 8 out of the 9 activities and participation chapters were covered; no categories of d6 domestic life were included. The three most frequently represented chapters were b1 Mental functions $(k=7,15 \%)$, e4 Attitudes $(k=7,15 \%)$, and e3 Support and relationships $(k=6,13 \%)$.

\section{Brief ICF Core Set for school-age children and adolescents (6-16 years old)}

Table 6 displays the categories were included in the Brief Set for school-age individuals (6-16 years old), along with their final rank order. It contains 55 second-level ICF categories (including the 47 Brief Common Set categories), with the categories distributed across the activities and participation component $(k=24,44 \%)$, environmental factors $(k=23,42 \%)$, and body functions $(k=8,14 \%)$. All five environmental factor chapters were represented. Except for d4 Mobility and d6 Domestic life, all the activities and participation chapters were also covered. The three most represented chapters were b1 Mental functions $(k=7,13 \%), \mathrm{d} 1$ Learning and applying knowledge $(k=7$, $13 \%)$, and e4 Attitudes $(k=7,13 \%)$.

\section{Brief ICF Core Set for older adolescents and adults ( $\geq 17$ years old)}

Table 7 shows the categories that were included in the Brief ICF Core Set for older adolescents and adults ( $\geq 17$ years old), along with their final rank order. The experts voted to include 52 second-level ICF categories for this set. Categories were mostly from the activities and participation component $(k=24,46 \%)$, followed by environmental factors $(k=21,40 \%)$ and body functions $(k=7,14 \%)$. Contrary to the Brief Core Sets for pre-schoolers and school-age children, not all five environmental factor chapters were represented in this set; e2 Natural environment and human-made changes were not covered. In addition, b760 Control of voluntary movement functions was not included in this set. The three most covered chapters were e4 Attitudes $(k=8,15 \%)$, b1 Mental functions $(k=7,13 \%)$, and d8 Major life areas $(k=6,12 \%)$.

\section{Discussion}

The aim of the international consensus conference described in this paper was to develop Comprehensive and Brief ICF Core Sets for ADHD based on the evidence collected 
Table 3 Second-level ICF categories included in the Comprehensive ICF Core Set for ADHD across the lifespan, along with the percentage of agreement for each category that was included
Second-level ICF category

$\%$ Agreement (Vote round)

b125 Dispositions and intra-personal functions

$100 \%$ (Vote B)

b130 Energy and drive functions

$85 \%$ (Vote A)

b134 Sleep functions

$95 \%$ (Vote A)

b140 Attention functions

$100 \%$ (Vote A)

b147 Psychomotor functions

$100 \%$ (Vote A)

b152 Emotional functions

$85 \%$ (Vote A)

b164 Higher level cognitive functions

$95 \%$ (Vote A)

b760 Control of voluntary movement functions

$100 \%$ (Vote B)

d160 Focusing attention

$100 \%$ (Vote A)

d161 Directing attention

$90 \%$ (Vote A)

d166 Reading

d170 Writing

d172 Calculating

d175 Solving problems

d177 Making decisions

d210 Undertaking a single task

d220 Undertaking multiple tasks

d230 Carrying out daily routine

d240 Handling stress and other psychological demands

$100 \%$ (Vote B)

$100 \%$ (Vote B)

$100 \%$ (Vote B)

95\% (Vote A)

$100 \%$ (Vote B)

$100 \%$ (Vote A)

$95 \%$ (Vote A)

$95 \%$ (Vote A)

$100 \%$ (Vote A)

95\% (Vote A)

$100 \%$ (Vote B)

$65 \%$ (Vote C)

$95 \%$ (Vote B)

$100 \%$ (Vote B)

$100 \%($ Vote A)

95\% (Vote A)

$100 \%$ (Vote B)

$100 \%$ (Vote B)

$100 \%$ (Vote B)

90\% (Vote A)

$100 \%$ (Vote A)

$95 \%$ (Vote A)

95\% (Vote A)

$90 \%$ (Vote A)

$90 \%$ (Vote A)

$100 \%$ (Vote A)

$80 \%$ (Vote A)

100\% (Vote A)

95\% (Vote A)

95\% (Vote A)

$90 \%$ (Vote A)

$100 \%$ (Vote B)

95\% (Vote A)

$100 \%$ (Vote A)

95\% (Vote A)

90\% (Vote C)

95\% (Vote A)

$75 \%$ (Vote C)

90\% (Vote A)

95\% (Vote A)

90\% (Vote A) 
Table 3 (continued)

\begin{tabular}{ll}
\hline Second-level ICF category & $\%$ Agreement (Vote round) \\
\hline e320 Friends & $100 \%$ (Vote A) \\
e325 Acquaintances, peers, colleagues, neighbours, and community members & $100 \%$ (Vote A) \\
e330 People in positions of authority & $100 \%$ (Vote A) \\
e340 Personal care providers and personal assistants & $60 \%$ (Vote C) \\
e355 Health professionals & $95 \%$ (Vote A) \\
e360 Other professionals & $85 \%$ (Vote A) \\
e410 Individual attitudes of immediate family members & $100 \%$ (Vote A) \\
e415 Individual attitudes of extended family members & $85 \%$ (Vote A) \\
e420 Individual attitudes of friends & $95 \%$ (Vote A) \\
e425 Individual attitudes of acquaintances, peers, colleagues, neighbours, and & $90 \%$ (Vote A) \\
community members & \\
e430 Individual attitudes of people in positions of authority & $80 \%$ (Vote A) \\
e440 Individual attitudes of personal care providers and personal assistants & $55 \%$ (Vote C) \\
e450 Individual attitudes of health professionals & $95 \%$ (Vote A) \\
e455 Individual attitudes of other professionals & $100 \%$ (Vote C) \\
e460 Societal attitudes & $95 \%$ (Vote A) \\
e465 Social norms, practices, and ideologies & $95 \%$ (Vote A) \\
e570 Social security services, systems, and policies & $100 \%$ (Vote B) \\
e575 General social support services, systems, and policies & $85 \%$ (Vote A) \\
e580 Health services, systems, and policies & $95 \%$ (Vote A) \\
e585 Education and training services, systems, and policies & $90 \%$ (Vote A) \\
e590 Labour and employment services, systems, and policies & $95 \%$ (Vote A) \\
\hline
\end{tabular}

through four international preparatory studies, i.e., a scoping review [36], an expert survey [37], a qualitative study [38], and a clinical cross-sectional study [39]. This aim was fulfilled by an international multiprofessional group of experts. The expert group decided to include categories in the Comprehensive Core Set for ADHD that highlight activities of daily living and functioning in various environments, while putting less emphasis on body functions and none on structures. The Brief Core Sets followed the same pattern, including categories taken predominantly from the activities and participation component and environmental factors. The activities and participation categories that were identified as characteristic of living with ADHD were diverse. They range from challenges with social relationships and interactions $[8,40]$ to academic achievement $[6,7]$, occupational functioning [7], and self-care [41]. Contrary to activities and participation, the body function categories were less heterogeneous, consisting mainly of $\mathrm{b} 1$ mental function categories. Nevertheless, physical aspects of the body, such as motor coordination, were included in the Comprehensive Core Set. This reflects the previous findings that suggest that the impact of ADHD extends beyond mental functions into other body processes, including voluntary movement functions [42].

Interestingly, during the consensus conference, the experts were generally less favourable to including body function categories in the ADHD Core Sets compared to activities and participation categories and environmental factors. One possible explanation might be that, since the conceptualisation of ADHD has historically been rooted in a biomedical framework, with its biomedical features already described in ICD-10 [23] and DSM-5 [5], the participating experts may have perceived the development of ICF Core Sets for ADHD as a chance to incorporate personal, social, and environmental aspects of the individual in a more holistic perspective of ADHD [25, 43]. Still, however, mental functions were covered in all age-specific brief sets, supporting the notion that ADHD is a persistent neurodevelopmental condition associated with cognitive challenges [44, 45]. Notably, motor coordination was included in all core sets, except for the older adolescent and adult version. The previous research findings on ADHD have shown motor coordination issues to persist into adulthood [46]. The absence of motor coordination may be related to greater emphasis adults with ADHD and their environment place on social/ relationship problems and subsequent effect on self-image and self-esteem than on the physical issues being present [47, 48]. Another explanation may be that motor coordination issues generally receive less attention in clinical practice compared to cognitive impairments [49].

In this bio-psycho-social perspective of ADHD, environmental factors seem to play an important role, as evidenced by the composition of the 5 core sets, i.e., each of the core sets is composed of at least $40 \%$ environmental 
Table 4 Second-level ICF categories included in the Common Brief ICF Core Set for ADHD across the lifespan, along with their final rank order per ICF component
Second-level ICF category

Final rank order $(1=$ most essential)

b125 Dispositions and intra-personal functions

b130 Energy and drive functions

b134 Sleep functions

b140 Attention functions

b147 Psychomotor functions

b152 Emotional functions

b164 Higher level cognitive functions

d160 focusing attention

d161 Directing attention

d175 Solving problems

d177 Making decisions

d220 Undertaking multiple tasks

d230 Carrying out daily routine

d240 Handling stress and other psychological demands

d250 Managing one's own behaviour

d571 Looking after one's safety

d710 Basic interpersonal interactions

d720 Complex interpersonal interactions

d760 Family relationships

d820 School education

d920 Recreation and leisure

e110 Products or substances for personal consumption

e115 Products and technology for personal use in daily living

e310 Immediate family

e320 Friends

(2) factors and 4 out of the 5 core sets cover all the environmental factor chapters. This is consistent with research that highlight selected environmental factors relevant in ADHD [17-19], argue for a better understanding of the environment factors that influence functional outcomes in ADHD [50, 51], and promote interventions that help individuals with ADHD to more optimally perform in key environmental contexts [52], such as education [53], vocation [54], and community participation [9].
There were some commonalities and differences with regard to environmental factor representation in the different age-specific sets. Common in all age-specific brief sets is category e 575 General social support services, systems, and policies, which demonstrates the importance of access to support services for the functioning of individuals with ADHD across the lifespan [50]. Principally, support services, systems, and policies, including social security, health, and education, were deemed important, as evidenced 
Table 5 Second-level ICF categories included in the Brief ICF Core Set for preschool aged children ( $0-5$ years old), along with their final rank order per ICF component
Second-level ICF category

Final rank order $(1=\text { most essential })^{\mathrm{a}}$

b125 Dispositions and intra-personal functions

b130 Energy and drive functions

b134 Sleep functions

b140 Attention functions

b147 Psychomotor functions

b152 Emotional functions

b164 Higher level cognitive functions

b760 Control of voluntary movement functions

d160 Focusing attention

d161 Directing attention

d175 Solving problems

d177 Making decisions

d210 Undertaking a single task

d220 Undertaking multiple tasks

d230 Carrying out daily routine

d240 Handling stress and other psychological demands

d250 Managing one's own behaviour

d350 Conversation

d440 Fine hand use

d571 Looking after one's safety

d710 Basic interpersonal interactions

d720 Complex interpersonal interactions

d750 Informal social relationships

d760 Family relationships

d820 School education

d880 Engagement in play

d920 Recreation and leisure

e110 Products or substances for personal consumption

e115 Products and technology for personal use in daily living

e250 Sound

e310 Immediate family

e315 Extended family

e320 Friends

e330 People in positions of authority

e340 Personal care providers and personal assistants

(6)

e355 Health professionals

e410 Individual attitudes of immediate family members

e415 Individual attitudes of extended family members

e430 Individual attitudes of people in positions of authority

e440 Individual attitudes of personal care providers and personal assistants

e450 Individual attitudes of health professionals

e460 Societal attitudes

e465 Social norms, practices, and Ideologies

e570 Social security services, systems, and policies

e575 General social support services, systems, and policies

(2)

e580 Health services, systems, and policies

e585 Education and training services, systems, and policies

${ }^{a}$ The rank order here does not comprise the categories that were included in the Brief Common Set 
Table 6 Second-level ICF categories included in the Brief ICF Core Set for school-aged children and adolescents of 6-16 years old, along with their final rank order per ICF component
Second-level ICF category

Final rank order $(1=$ most

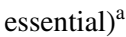

b125 Dispositions and intra-personal functions

b130 Energy and drive functions

b134 Sleep functions

b140 Attention functions

b147 Psychomotor functions

b152 Emotional functions

b164 Higher level cognitive functions

b760 Control of voluntary movement functions

d160 Focusing attention

d161 Directing attention

d166 Reading

d170 Writing

d172 Calculating

d175 Solving problems

d177 Making decisions

d210 Undertaking a single task

d220 Undertaking multiple tasks

d230 Carrying out daily routine

d240 Handling stress and other psychological demands

d250 Managing one's own behaviour

d350 Conversation

d520 Caring for body parts

d570 Looking after one's health

d571 Looking after one's safety

d710 Basic interpersonal interactions

d720 Complex interpersonal interactions

d740 Formal relationships

d750 Informal social relationships

d760 Family relationships

d820 School education

d880 Engagement in play

d920 Recreation and leisure

e110 Products or substances for personal consumption

e115 Products and technology for personal use in daily living

e125 Products and technology for communication

e130 Products and technology for education

e240 Light

e250 Sound

e310 Immediate family

e315 Extended family

e320 Friends

e325 Acquaintances, peers, colleagues, neighbours, and community members

e330 People in positions of authority

e355 Health professionals

e410 Individual attitudes of immediate family members

e415 Individual attitudes of extended family members

e420 Individual attitudes of friends

e430 Individual attitudes of people in positions of authority

e450 Individual attitudes of health professionals 
Table 6 (continued)

\begin{tabular}{ll}
\hline Second-level ICF category & $\begin{array}{l}\text { Final rank order }(1=\text { most } \\
\text { essential })^{\mathrm{a}}\end{array}$ \\
\hline e460 Societal attitudes & \\
\hline e465 Social norms, practices, and ideologies & \\
e570 Social security services, systems, and policies \\
e575 General social support services, systems, and policies \\
e580 Health services, systems, and policies \\
e585 Education and training services, systems, and policies
\end{tabular}

${ }^{a}$ The rank order here does not comprise the categories that were included in the brief common set

by the inclusion of corresponding categories in the Common Brief Set. This is especially relevant when considering the transition of adolescents with ADHD to adulthood, as health care and intervention programs appropriate for individuals with ADHD undergoing this period of transition are limited $[55,56]$. Another common representation is the environmental factor chapter e4 Attitudes that was covered in each respective age-specific set. This may reflect the notion that ADHD is still not fully accepted as a legitimate medical condition by affected families and a large portion of society [57-59]. A key difference that was found between the different age-specific brief sets was the lack of categories from the e2 Natural environment and human-made changes to environment chapter (i.e., sound, light) in the older adolescent and adult version. This is supported by literature which indicates that older adolescents and adults with ADHD seem to develop over time certain coping strategies that help them to become less susceptible to loud noises or bright lights [60]. To understand the complex interplay between abilities and disabilities with age as a modifier better, further research is needed.

The environmental factors included in the ADHD Core Sets can be useful in describing possible facilitators and barriers of functioning in various environments. However, they may not be comprehensive or detailed enough for optimal applicability in interventions. For example, e310 Immediate family, e315 Extended family, and e330 People in positions of authority are insufficiently detailed for an accurate assessment of an individual's social supports [61]. Despite this, the ADHD Core Sets can facilitate awareness raising about the value of environmental factors, especially in encouraging the ADHD community to explore existing attitudes and social beliefs $[62,63]$. This is especially relevant when considering cultural differences. Although symptoms of neurodevelopmental disorders may be similar across cultures, the way that symptoms are perceived, interpreted, or accepted is not [64]. Taking this into account, as well as WHO's push for internationality, efforts were made to ensure that cultural and attitudinal differences were considered in developing the ICF Core Sets for ADHD. Equipping stakeholders with useful tools that can also be applied in exploring the attitudinal environment of individuals with ADHD may enable them to more effectively identify and address environmental barriers, such as social stigma, with knowledge transfer and other interventions.

Despite the numerous advantages of recognizing environmental factors, these have been neglected by the common standardised process of diagnosing ADHD. For example, the two major diagnostic systems, ICD-10 [21] and DSM-5 [5], do not take environmental factors into account. Interestingly, individuals diagnosed with ADHD and their caregivers seem to emphasize the importance of environmental factors more than other stakeholders as shown by the comparison of the qualitative study results [38] with the results of the scoping review [36] and expert survey [37].

\section{Study limitations}

There were some challenges faced in developing the ADHD Core Sets that deserve attention, most of which have also been discussed in the publications on the preparatory studies [36-39]. First, although all six WHO world regions were represented in the preparatory studies and in the international consensus conference, parts of the world were not equally represented, potentially causing a risk that culturesensitive categories were overlooked. For example, there was considerable difficulty to identify and recruit ADHD experts from different parts of the world, e.g., Africa other than South Africa, to participate in the consensus conference. To address this issue, the conference participants were regularly reminded to discuss country and culture-specific aspects that may impact the applicability of the ICF Core Sets for ADHD and consider these aspects in their voting decisions.

Second, despite efforts to achieve a broad representation of disciplines, some professional groups were underrepresented. For instance, few speech-language pathologists and nurses participated in the consensus conference. Perhaps, the reason for the relatively low number of categories related to language development or gastrointestinal functions. 
Table 7 Second-level ICF categories included in the Brief ICF Core Set for older adolescents and adults ( $\geq 17$ years old), along with their final rank order per ICF component
Second-level ICF category

Final rank order $(1=$ most

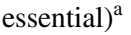

b125 Dispositions and intra-personal functions

b130 Energy and drive functions

b134 Sleep functions

b140 Attention functions

b147 Psychomotor functions

b152 Emotional functions

b164 Higher level cognitive functions

d160 Focusing attention

d161 Directing attention

d175 Solving problems

d177 Making decisions

d220 Undertaking multiple tasks

d230 Carrying out daily routine

d240 Handling stress and other psychological demands

d250 Managing one's own behaviour

d475 Driving

d570 Looking after one's health

d571 Looking after one's safety

d640 Doing housework

d710 Basic interpersonal interactions

d720 Complex interpersonal interactions

d740 Formal relationships

d760 Family relationships

d770 Intimate relationships

d820 School education

d825 Vocational training

d845 Acquiring, keeping and terminating a job

d850 Remunerative employmen

e110 Products or substances for personal consumption

e115 Products and technology for personal use in daily living

e125 Products and technology for communication

e310 Immediate family

e315 Extended family

e320 Friends

e330 People in positions of authority

e355 Health professionals

e410 Individual attitudes of immediate family members

e415 Individual attitudes of extended family members

(8)

e420 Individual attitudes of friends

e425 Individual attitudes of acquaintances, peers, colleagues, neighbours, and community members

e430 Individual attitudes of people in positions of authority

e450 Individual attitudes of health professionals

e460 Societal attitudes

e465 Social norms, practices, and ideologies

e570 Social security services, systems, and policies 
Table 7 (continued)

\begin{tabular}{ll}
\hline Second-level ICF category & $\begin{array}{l}\text { Final rank } \\
\text { order }(1=\text { most } \\
\text { essential })^{\mathrm{a}}\end{array}$ \\
\hline
\end{tabular}

e575 General social support services, systems, and policies

(1)

e580 Health services, systems, and policies

e585 Education and training services, systems, and policies

e590 Labour and employment services, systems, and policies

(3)

${ }^{\mathrm{a}}$ The rank order here does not comprise the categories that were included in the brief common set
Finally, while individuals with ADHD and family members were involved in the preparatory studies to capture their unique views and experiences, they were not expressly recruited to be part of the consensus conference. Since shared decision-making between researchers and stakeholders in neurodevelopmental disorders is desirable, future research should actively recruit the input of individuals with ADHD and family [65, 66].

\section{Applications of the ICF Core Sets for ADHD}

A novel and integral part of the diagnostic procedures and criteria recommended for ADHD in the upcoming ICD-11 is the use of ICF categories to describe the impact of a health condition on individual functioning [25]. The ICF Core Sets for ADHD may potentially guide the selection of categories used in the ICD-11, hereby marking a paradigm shift in the diagnostic assessment of ADHD. If realised, the international operationalisation of ADHD will not only disorderbased, but also contain functioning-related health information that can be used to reflect the unique situation of the patient. The ICF Core Sets for ADHD can enrich diagnostic decision-making and treatment planning with a broad range of information that considers relevant environmental factors and the specific needs of the individual.

Another area of application may be resource allocation. With the ICF, and the Core Sets derived from it, it is possible to describe an individual's strengths and ADHD-associated functioning problems in a comprehensive and individualised manner. With this in mind, the ICF and ICF Core Sets can serve as a guide to more individualised rather than a solely diagnosis-based resource allocation and reimbursement in health care and in education $[29,67,68]$.

To increase the utility of the ADHD Core Sets in these and other application areas, it would be advisable to develop standardised user-friendly ICF Core Set-based tools, such as a questionnaire with a scale that apply established measurement standards, or observation schedules and interviews. Comparable with scales derived from ICD-10 or DSM-5 diagnostic criteria, practitioners may find using the ADHD Core Sets easier and more practical in a form that they are familiar with, such as a questionnaire or interview instrument. An example of an ICF Core Set-based instrument is the ASAS Health Index for spondyloarthritis [69]. Another clinical and research application of the ICF Core Sets is the toolbox of psychometrically sound measures that cover the content of the ICF Core Sets for children and youth with cerebral palsy. This toolbox lays the groundwork for standardising the measurement and reporting of functioning information in cerebral palsy and for facilitating the comparison of study results from all over the world [70]. Beyond developing tangible tools for clinical use and research, we envision the ICF Core Sets for ADHD as a driver of service quality improvement and functioning, informed policy-making at the local, regional, and national levels.

Acknowledgements The development of ICF Core Sets for ADHD is a cooperative effort of the ICF Research Branch, a partner within the WHO Collaboration Centre for the Family of International Classifications in Germany (at DIMDI), the European Network of Hyperkinetic Disorders (EUNETHYDIS), and the Centre of Neurodevelopmental Disorders at the Karolinska Institutet (KIND) in Sweden. The development of ICF Core Sets for ADHD is supported by the Swedish Research Council in partnership with FAS (now renamed FORTE), FORMAS, and VINNOVA (trans-disciplinary research programs on child and youth mental health, grant nr. 259-2012-24). This paper recognizes the invaluable contribution of individuals with ADHD, their family members, experts, and other stakeholders, as well as past members of the project (Elles de Schipper) who contributed to the preparatory studies, organisation, and administration of the ADHD ICF Core Sets development, the experts who participated in the consensus conference (Ann-Christin Eliasson, Anna Backman, Dido Green, Efrain Torres-Montalvo, Fredrika Gauffin, Helena Hemmingsson, James Shelly, José Carlos Dias, Lindsey Pollock, Lino Palacios-Cruz, Lisa Thorell, Marisa Viljoen, Martina Hedenius, Mashael Alshalaan, Meena Shiledar, Michael Jung, Philip Hazell, Rukhshana Sholapurwala, Tatja Hirvikoski and Věra Vojtová), and the Steering Committee (authors DC, SFG, MG, MH, SK, FL, LR, PdV; Omar Al-Modafyer, Heidi Bernhardt, Judith Hollenweger, Michael Rösler, Susan Swedo, Rosemary Tannock, Berihan Üstün). We also acknowledge the important efforts of the assistants who recorded the discussions and votes that took place during the WG and plenary sessions of the consensus conference (Adina Iatan, Anneli Sjöberg, Annelies van't Westeinde, Charlie Åkerblom, Philip Ivers Ohlsson).

\section{Compliance with ethical standards}

Conflict of interest No author declares a direct conflict of interest related to this article. Sven Bölte discloses that he has in the last 5 years acted as an author, consultant, or lecturer for Shire, Medice, Roche, 
Eli Lilly, Prima Psychiatry, GLGroup, System Analytic, Kompetento, Expo Medica, and Prophase. He receives royalties for text books and diagnostic tools from Huber/Hogrefe, Kohlhammer, and UTB. David Coghill discloses that he has in the last 5 years acted as an author, consultant, or lecturer for Shire, Medice, Bristol Myers Squib, and Eli Lilly. He receives royalties for text books from Oxford University Press. Luis A Rohde was on the speakers' bureau and/or acted as consultant for Eli-Lilly, Janssen-Cilag, Medice, Novartis, and Shire in the past 3 years. He receives authorship royalties from Oxford Press and ArtMed. He also received travel award to attend the 2015 WFADHD and 2016 AACAP meetings. The ADHD Outpatient Programs chaired by him received unrestricted educational and research support from the following pharmaceutical companies in the past 3 years: Eli-Lilly, Janssen-Cilag, Novartis, and Shire. Petrus J de Vries has been on the study steering committee and advisory board for clinical trials and guideline development in tuberous sclerosis complex funded by Novartis.

Open Access This article is distributed under the terms of the Creative Commons Attribution 4.0 International License (http://creativeco mmons.org/licenses/by/4.0/), which permits unrestricted use, distribution, and reproduction in any medium, provided you give appropriate credit to the original author(s) and the source, provide a link to the Creative Commons license, and indicate if changes were made.

\section{References}

1. Thomas R, Sanders S, Doust J, Beller E, Glasziou P (2015) Prevalence of attention deficit/hyperactivity disorder: a systematic review and meta-analysis. Pediatrics 135:994-1001

2. Willcutt EG (2012) The prevalence of DSM-IV attention deficit/ hyperactivity disorder: a meta-analytic review. Neurotherapeutics 9:490-499

3. Polanczyk G, de Lima MS, Horta BL, Biederman J, Rohde LA (2007) The worldwide prevalence of ADHD: a systematic review and metaregression analysis. Am J Psychiatry 164:942-948

4. Simon V, Czobor P, Bálint S, Mészáros Á, Bitter I (2009) Prevalence and correlates of adult attention-deficit hyperactivity disorder: meta-analysis. Br J Psychiatry 194:204-211

5. American Psychiatric Association (2013) Diagnostic and statistical manual of mental disorders (DSM-5). Pilgrim Press, Washington

6. Arnold EL, Hodgkins P, Kahle J, Madhoo M, Kewley G (2015) Long-term outcomes of ADHD: academic achievement and performance. J Atten Disord. https://doi.org/10.1177/1087054714 566076

7. Fredriksen M, Dahl AA, Martinsen EW, Klungsoyr O, Faraone SV, Peleikis DE (2014) Childhood and persistent ADHD symptoms associated with educational failure and long-term occupational disability in adult ADHD. Atten Defic Hyperact Disord 6:87-99

8. Hoza B (2007) Peer functioning in children with ADHD. J Pediatr Psychol 32:655-663

9. Knecht C, de Alvaro R, Martinez-Raga J, Balanza-Martinez V (2015) Attention-deficit hyperactivity disorder (ADHD), substance use disorders and criminality: a difficult problem with complex solutions. Int J Adolesc Med Health 27:163-175

10. Doshi JA, Hodgkins P, Kahle J, Sikirica V, Cangelosi MJ, Setyawan J, Erder MH, Neumann PJ (2012) Economic impact of childhood and adult attention-deficit/hyperactivity disorder in the United States. J Am Acad Child Adolesc Psychiatry 51:990-1002

11. Biederman J, Petty CR, Woodworth KY, Lomedico A, Hyder LL, Faraone SV (2012) Adult outcome of attention-deficit/ hyperactivity disorder: a controlled 16-year follow-up study. J Clin Psychiatry 73:941-950

12. Levy S, Katusic SK, Colligan RC, Weaver AL, Killian JM, Voigt RG, Barbares WJ (2014) Childhood ADHD and risk for substance dependence in adulthood: a longitudinal, population-based study. PLoS One 9:e105640

13. Jonsson U, Alaie I, Löfgren-Wilteus A, Zander E, Marschik PB, Coghill D, Bölte S (2017) Annual research review: quality of life and childhood mental and behavioural disorders - a critical review of the research. J Child Psychol Psychiatry 58:439-469

14. Lensing MB, Zeiner P, Sandvik L, Opjordsmoen S (2015) Quality of life in adults aged 50+ with ADHD. J Atten Disord 19:405-413

15. Dalsgaard S, Dinesen Østergaard S, Leckman JF, Mortensen PB, Gjørtz Pedersen M (2015) Mortality in children, adolescents, and adults with attention deficit hyperactivity disorder: a nationwide cohort study. Lancet 385:2190-2196

16. Verheul I, Block J, Burmeister-Lamp K, Thurik R, Tiemeier $\mathrm{H}$, Turturea R (2015) ADHD-like behavior and entrepreneurial intentions. Small Bus Econ 45:85-101

17. White HA, Shah P (2016) Scope of semantic activation and innovative thinking in college students with ADHD. Creat Res J 28:275-282

18. Newark PE, Elsässer M, Stieglitz R-D (2016) Self-esteem, selfefficacy and resources in adults with ADHD. J Atten Disord 20:279-290

19. Hirvikoski T, Waaler E, Alfredsson J, Pihlgren C, Holmström A, Johnson A, Rück J, Wiwe C, Bothén P, Nordström AL (2011) Reduced ADHD symptoms in adults with ADHD after structured skills training group: results from a randomized controlled trial. Behav Res Ther 49:175-185

20. Chan E, Fogler JM, Hammerness PG (2016) Treatment of attention-deficit/hyperactivity disorder in adolescents: a systematic review. JAMA 315:1997-2008

21. Veloz Texeira MCT, Marino RLF, Carreiro LRR (2015) Associations between inadequate parenting practices and behavioral problems in children and adolescents with attention deficit hyperactivity disorder. Sci World. https://doi. org $/ 10.1155 / 2015 / 683062$

22. World Health Organization (2001) International classification of functioning, disability and health: ICF. World Health Organization, Geneva

23. World Health Organization (2011) International statistical classification of diseases and related health problems-10th revision: ICD-10. World Health Organization, Geneva

24. World Health Organization (2007) International classification of functioning, disability and health: children and youth version: ICF-CY. World Health Organization, Geneva

25. Escorpizo R, Kostanjsek N, Kennedy C, Robinson Nicol MM, Stucki G, Ustün TB, Functioning Topic Advisory Group (fTAG) of the ICD-11 Revision (2013) Harmonizing WHO's international classification of diseases (ICD) and international classification of functioning, disability and health (ICF): importance and methods to link disease and functioning. BMC Public Health 13:742

26. Bölte S (2009) The ICF and its meaning for child and adolescent psychiatry. Z Kinder- und Jugendpsych und Psychother 37:495-497

27. Castro S, Pinto AI (2013) Identification of core functioning features for assessment and intervention in autism spectrum disorders. Disabil Rehabil 35:125-133

28. Schraner I, De Jonge D, Layton N, Bringolf J, Molenda A (2008) Using the ICF in economic analyses of assistive technology systems: methodological implications of a user standpoint. Disabil Rehabil 30:916-926 
29. Hopfe M, Prodinger B, Bickenbach JE, Stucki G (2017) Optimizing health system response to patient's needs: an argument for the importance of functioning information. Disabil Rehabil. https:// doi.org/10.1080/09638288.2017.1334234

30. Selb M, Escorpizo R, Kostanjsek N, Stucki G, Üstün B, Cieza A (2015) A guide on how to develop an international classification of functioning, disability and health core set. Eur J Phys Rehabil Med 51:105-117

31. Schiariti V, Selb M, Cieza A, O‘Donnell M (2015) international classification of functioning, disability and health core sets for children and youth with cerebral palsy: a consensus meeting. Dev Med Child Neurol 57:149-158

32. Cieza A, Chatterji S, Andersen C, Cantista P, Herceg M, Melvin J, Stucki G, de Bie R (2004) ICF core sets for depression. J Rehabil Med 44:128-134

33. Ayuso-Mateos JL, Avila CC, Anaya C, Cieza A, Vieta E, Bipolar Disorders Core Sets Expert Group (2013) Development of the international classification of functioning, disability and health core sets for bipolar disorders: results of an international consensus process. Disabil Rehabil 35:2138-2146

34. Bölte S, De Schipper E, Holtmann M, Karande S, de Vries PJ, Selb M, Tannock R (2014) Development of ICF core sets to standardize assessment of functioning and impairment in ADHD: the path ahead. Eur Child Adolesc Psychiatry 12:1139-1148

35. Cieza A, Geyh S, Chatterji S, Kostanjsek N, Üstün B, Stucki G (2005) ICF linking rules: an update based on lessons learned. J Rehabil Med 37:212-218

36. De Schipper E, Lundequist A, Löfgren-Wilteus A, Coghill D, de Vries PJ, Granlund M, Holtmann M, Jonsson U, Karande S, Levy F, Al-Modayfer O, Rohde L, Tannock R, Tonge B, Bölte S (2015) A comprehensive scoping review of ability and disability in ADHD using the international classification of functioning, disability and health-children and youth version (ICF-CY). Eur Child Adolesc Psychiatry 24:859-872

37. De Schipper E, Mahdi S, Coghill D, de Vries PJ, Shur-Fen Gau S, Granlund M, Holtmann M, Karande S, Levy F, Almodayfer O, Rohde L, Tannock R, Bölte S (2015) Towards an ICF core set for ADHD: a worldwide expert survey on ability and disability. Eur Child Adolesc Psychiatry 24:1509-1521

38. Mahdi S, Viljoen M, Massuti R, Selb M, Almodayfer O, Karande S, de Vries PJ, Rohde L, Bölte S (2017) An international qualitative study of ability and disability in ADHD using the WHO-ICF framework. Eur Child Adolesc Psychiatry 10:1219-1231

39. Mahdi S, Ronzano N, Knüppel A, Dias JC, Albdah A, Chien-Ho L, Almodayfer O, Bluschke A, Karande S, Huang H-L, Christiansen H, Granlund M, de Vries PJ, Coghill D, Tannock R, Rohde L, Bölte S (2017) An international clinical study of ability and disability in ADHD using the WHO-ICF framework. Eur ChildAdolesc Psychiatry [in press]

40. Michielsen M, Comijs HC, Aartsen MJ, Semeijn EJ, Beekman ATF, Deeg DJH, Kooij S (2015) The relationships between ADHD and social functioning and participation in older adults in a population-based study. J Atten Disord 19:368-379

41. Barkley RA (2014) ADHD and injuries: accidental and selfinflicted. ADHD Rep 22:1-8

42. Fliers E, Rommelse N, Vermeulen SHHM, Altink M, Buschgens CJM, Faraone SV, Sergeant JA, Franke B, Buitelaar JK (2008) Motor coordination problems in children and adolescents with ADHD rated by parents and teachers: effects of age and gender. J Neural Transm 115:211-220

43. Hwu Y-J, Coates VE, Boore JRP (2001) The evolving concept of health in nursing research: 1988-1998. Patient Educ Couns $42: 105-114$

44. Sonuga-Barke E, Bitsakou P, Thompson M (2010) Beyond the dual pathway model: evidence for the dissociation of timing, inhibitory, and delay-related impairments in attention deficit/ hyperactivity disorder. J Am Acad Child Adolesc Psychiatry 49:345-355

45. Sergeant JA (2005) Modeling attention-deficit/hyperactivity disorder: a critical appraisal of cognitive-energetic model. Biol Psychiatry $57: 1248-1255$

46. Stray LL, Kristensen $\varnothing$, Lomeland M, Skorstad M, Stray T, Tønnessen FE (2013) Motor regulation problems and pain in adults diagnosed with ADHD. Behav Brain Funct 9:1-10

47. Schrevel SJC, Dedding C, van Aken JA, Broerse JEW (2016) "Do I need to become someone else?" A qualitative exploratory study into the experiences and needs of adults with ADHD. Health Expect 19:39-48

48. Michielsen M, de Kruif JT, Comijs HC, van Mierlo S, Semeijn EJ, Beekman AT, Deeg DJ, Kooij JJ (2015) The burden of ADHD in older adults: a qualitative study. J Atten Disord. https://doi. org/10.1177/1087054715610001

49. Fliers EA, Franke B, Buitelaar JK (2011) Motor problems in children with ADHD receive too little attention in clinical practice. Ned Tjidschr Geneeskd 155:A3559

50. Ayyash H, Sankar S, Merriman H, Vogt C, Earl T, Shah K, Banerjee S (2013) Multidisciplinary consensus for the development of ADHD services: the way forward. Clin Govern Int J 18:30-38

51. Tarver J, Daley D, Sayal K (2014) Beyond symptom control for attention-deficit hyperactivity disorder (ADHD): what can parents do to improve outcomes? Child Care Health Dev 41:1-14

52. Tarver J, Daley D, Sayal K (2014) Attention-deficit hyperactivity disorder (ADHD): an updated review of the essential facts. Child Care Health Dev 40:762-774

53. DuPaul GJ, Gormley MJ, Laracy SD (2014) School-based interventions for elementary school students with adHD. Child Adolesc Psychiatric Clin N Am 23:687-697

54. Adamou M, Arif M, Asherson P, Tar-Ching A, Bolea B, Coghill D, Guðjónsson G, Halmøy A, Hodgkins P, Müller U, Pitts M, Trakoli A, Williams N, Young S (2013) Occupational issues of adults with ADHD. BMC Psychiatry 13:59-65

55. Ginsberg Y, Beusterjen KM, Amos K, Jousselin C, Asherson P (2014) The unmet needs of all adults with ADHD are not the same: a focus on Europe. Expert Rev Neurother 14:799-812

56. Matheson L, Asherson P, Wong ICK, Hodgkins P, Setyawan J, Sasane R, Clifford S (2013) Adult ADHD patient experiences of impairment, service provision and clinical management in England: a qualitative study. BMC Health Serv Res 13:184

57. Lebowitz MS (2016) Stigmatization of ADHD: a developmental review. J Atten Disord 20:199-205

58. dosReis S, Barksdale CL, Sherman A, Maloney K, Charach A (2010) Stigmatizing experiences of parents of children with a new diagnosis of ADHD. Psychiatr Serv 61:811-816

59. Lawton KE, Gerdes AC, Haack LM, Schneider B (2014) Acculturation, cultural values, and latino parental beliefs about the etiology of ADHD. Adm Policy Ment Health 41:189-204

60. Ek A, Isaksson G (2013) How adults with ADHD get engaged in and perform everyday activities. Scand J Occup Ther 20:282-291

61. Zakirova-Engstrand R, Granlund M (2009) The International classification of functioning, disability and health -children and youth (ICF-CY): testing its utility in classifying information from eco-cultural family interviews with ethnically diverse families with children with disabilities in Kyrgyzstan. Disabil Rehabil 31:1018-1030

62. Hinshaw SP, Scheffler RM, Fulton BD, Aase H, Banaschewski T, Cheng W, Mattos P, Holte A, Levy F, Sadeh A, Sergeant JA, Taylor E, Weiss MD (2011) International variation in treatment procedures for ADHD: social context and recent trends. Psychiatr Serv 62:459-464

63. Asherson P, Akehurst R, Kooij S, Huss M, Beusterien K, Sasané R, Gholizadeh S, Hodgkins P (2012) Under diagnosis of adult 
ADHD: cultural influences and societal burden. J Atten Disord $16: 20-38$

64. Moldavsky M, Sayal K (2013) Knowledge and attitudes about attention-deficit/hyperactivity disorder (ADHD) and its treatment: the views of children, adolescents, parents, teachers and healthcare professionals. Curr Psychiatry Rep 15:377

65. Fridman M, Banaschewski T, Sikirica V, Quintero J, Erder MH, Chen KS (2017) Caregiver perspective on pediatric attention-deficit/hyperactivity disorder: medication satisfaction and symptom control. Neuropsychiatr Dis Treat 13:443-455

66. Sikirica V, Flood E, Dietrich CN, Quintero J, Harpin V, Hodgkins P, Skrodzki K, Beusterien K, Erder HM (2015) Unmet needs associated with attention-deficit/hyperactivity disorder in eight european countries as reported by caregivers and adolescents: results from qualitative research. Patient 8:269-281
67. Escorpizo R, Stucki G (2013) Disability evaluation, social security, and the international classification of functioning, disability and health: the time is now. J Occup Environ Med 55:644-651

68. Escorpizo R, Brage S, Homa D, Stucki G (2015) Handbook of vocational rehabilitation and disability evaluation: application and implementation of the ICF. Springer International Publishing, Switzerland

69. Kiltz U, van der Heijde D, Boonen A, Braun J (2014) The ASAS health index (ASAS HI) - a new tool to assess the health status of patients with spondyloarthritis. Clin Exp Rheumatol 32:105-108

70. Schiariti V, Tatla S, Sauve K, O’Donnell M (2017) Toolbox of multiple-item measures aligning with the ICF Core Sets for children and youth with cerebral palsy. Eur J Paediatr Neurol 21:252-263 